\title{
Evidence for variable gene expression in a large inbred kindred with autosomal recessive spondylocostal dysostosis
}

\author{
Peter D Turnpenny, Richard J Thwaites, Farid N Boulos
}

\begin{abstract}
Seven members of a large inbred kindred with autosomal recessive spondylocostal dysostosis were examined clinically, radiographically, and sonographically. The subjects were three adults, one adolescent, and three children under 3 years of age. One child was the offspring of a first cousin marriage which showed quasi-dominant inheritance. Six subjects had short stature owing to widespread vertebral dyssegmentation with variable reduction in rib number and rib fusion. One subject was of normal stature, had limited vertebral dyssegmentation, an extra rib, and no rib fusion. Five subjects showed the plagiocephaly-torticollis sequence. Four of the five male subjects had inguinal herniation on one or both sides. All subjects had normal renal ultrasonography. The youngest subject died of cardiopulmonary complications and is thought to represent one extreme in the expressivity of the gene in this kindred.
\end{abstract}

Spondylocostal dysostosis is a heterogeneous disorder of vertebral dyssegmentation in which three distinct entities are clearly described. Jarcho and Levin ${ }^{1}$ were the first to describe a severe autosomal recessive form of a syndrome which now bears their names and is also referred to as spondylocostal dysostosis type I. In this condition, abnormal vertebral segmentation is often associated with a decreased number of ribs which have a 'crowded' origin from the thoracic

Paediatric Department, The Nazareth Hospital, PO Box 11, 16100 Nazareth, Israel.

P D Turnpenny, R J Thwaites

Radiology Department, The Nazareth Hospital, PO Box 11, 16100 Nazareth, Israel.

F N Boulos

Correspondence to Dr Turnpenny, Department of Medical Genetics, Aberdeen University Medical School, Foresterhill, Aberdeen AB9 2ZB.

Received for publication 29 May 1990.

Accepted for publication 22 June 1990. vertebral bodies and 'fan out' to give a characteristic 'crab-like' appearance of the thorax on $x$ ray. Death in infancy owing to respiratory insufficiency is the rule. Further reports of this condition have highlighted a Puerto Rican ancestry in many cases. ${ }^{2-5}$ The condition is amenable to prenatal diagnosis by ultrasonography. ${ }^{5-7}$

A benign form of spondylocostal dysostosis showing autosomal dominant inheritance has been described. ${ }^{8-10}$ The main complications are relative immobility of the spine and pain and weakness associated with an upright posture.

Benign autosomal recessive spondylocostal dysostosis is the most frequently described entity within the group. ${ }^{71-18}$ Within this entity, however, there are different phenotypes with, for instance, obvious differences in the shoulder span between cases described by Beighton and Horan, ${ }^{17}$ and those described by Castroviejo et al. ${ }^{12}$ In addition, a variety of associated malformations have been described, ${ }^{19-21}$ often relating to the structures which arise from the paraxial mesoderm in embryological life. Such cases begin to resemble malformations following the VATER or VACTERL pattern. There is an additional category of cases of spondylocostal dysostosis associated with miscellaneous malformations. ${ }^{22-24}$ An attempt has been made to delineate the groups by phenotype cluster analysis. ${ }^{21}$

The subjects of this study are an Arab family who were identified after the birth of two children in the pedigree, subjects V1.1 and V1.3 in fig 1. It was decided to examine them clinically, radiographically, and the renal system non-invasively by ultrasound. Seven subjects were identified and this is thought to be the largest number so far available for study within a single kindred.

\section{Materials and methods}

The pedigree (fig 1) was constructed from our own knowledge of the family and from data available from the area cytogenetics service. Affected subjects were identified by direct questioning of the family.

A clinical examination was conducted and the following data obtained: height, sitting height, span, and head and chest circumference. 


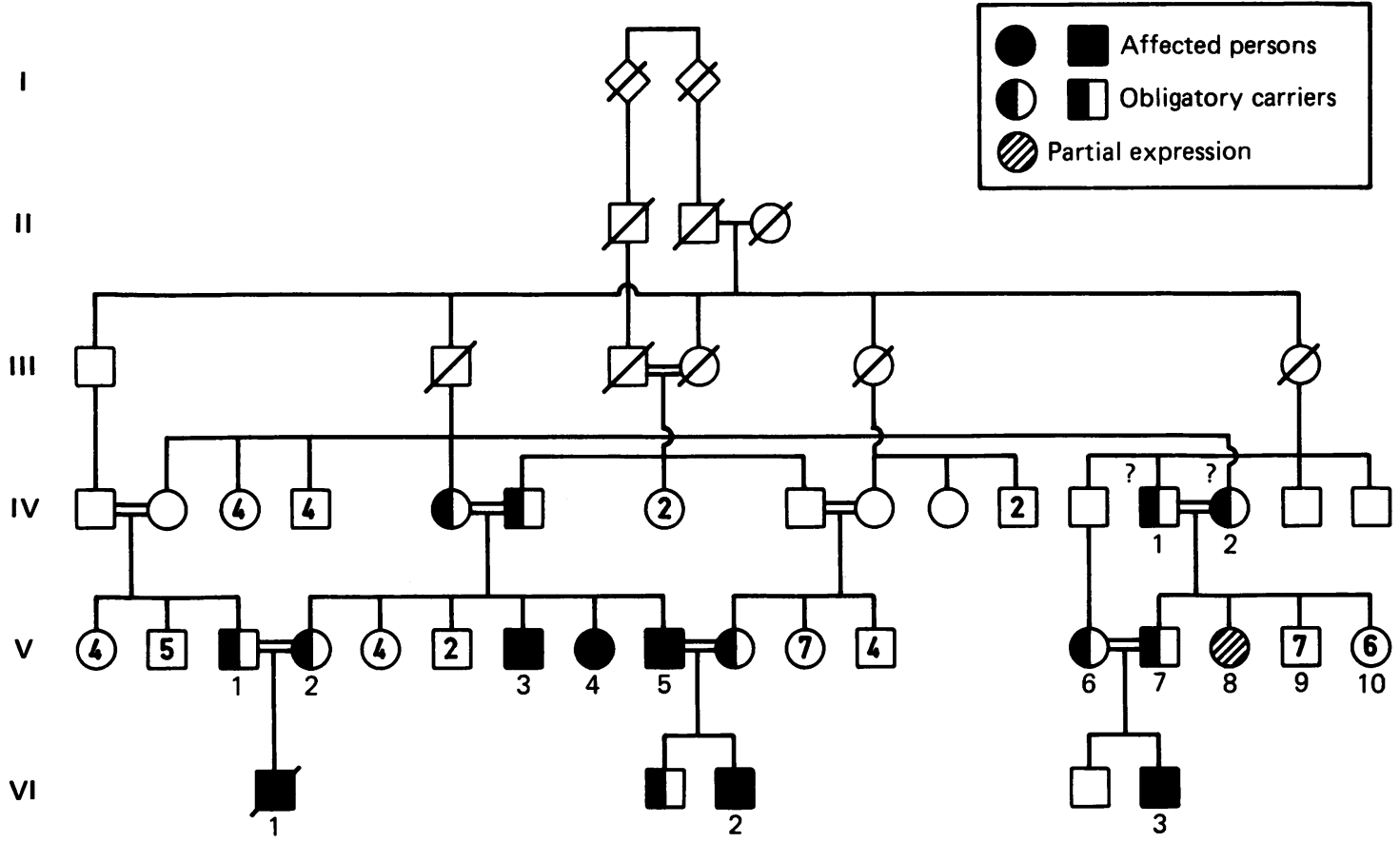

Figure 1 Family pedigree.

Spinal radiographs of all the affected subjects were made together with two sets of parents who were obligatory carriers for the gene. Renal ultrasonography was performed in all cases. Karyotyping (G banding) was done on two of the affected children. A necropsy was performed on the child VI.1 who died.

\section{Results}

All the affected subjects in this large inbred kindred are the offspring of consanguineous marriages, leaving no doubt that the mode of inheritance is autosomal recessive. The father to son transmission, V.5 to VI.2, is an example of quasi-dominance with the safe assumption that the partner of V.5 is an obligatory carrier. Many other consanguineous marriages existed in the pedigree but only those in direct line to the affected cases are included.

The results are summarised in tabulated form in the table. The general stature in an affected adult is shown in figs 2 and 3. Typical radiological findings are illustrated in figs 4 to 6 , contrasting a case of mild involvement of the lumbar spine (fig 5) with one showing severe disruption (fig 6). Similarly, the appearances in a child (fig 4) can be compared with those of an adult (figs 5 and 6) and it is noteworthy that scoliosis is remarkably non-progressive over the age range of these subjects. There were no apparent neurological complications, though compression of

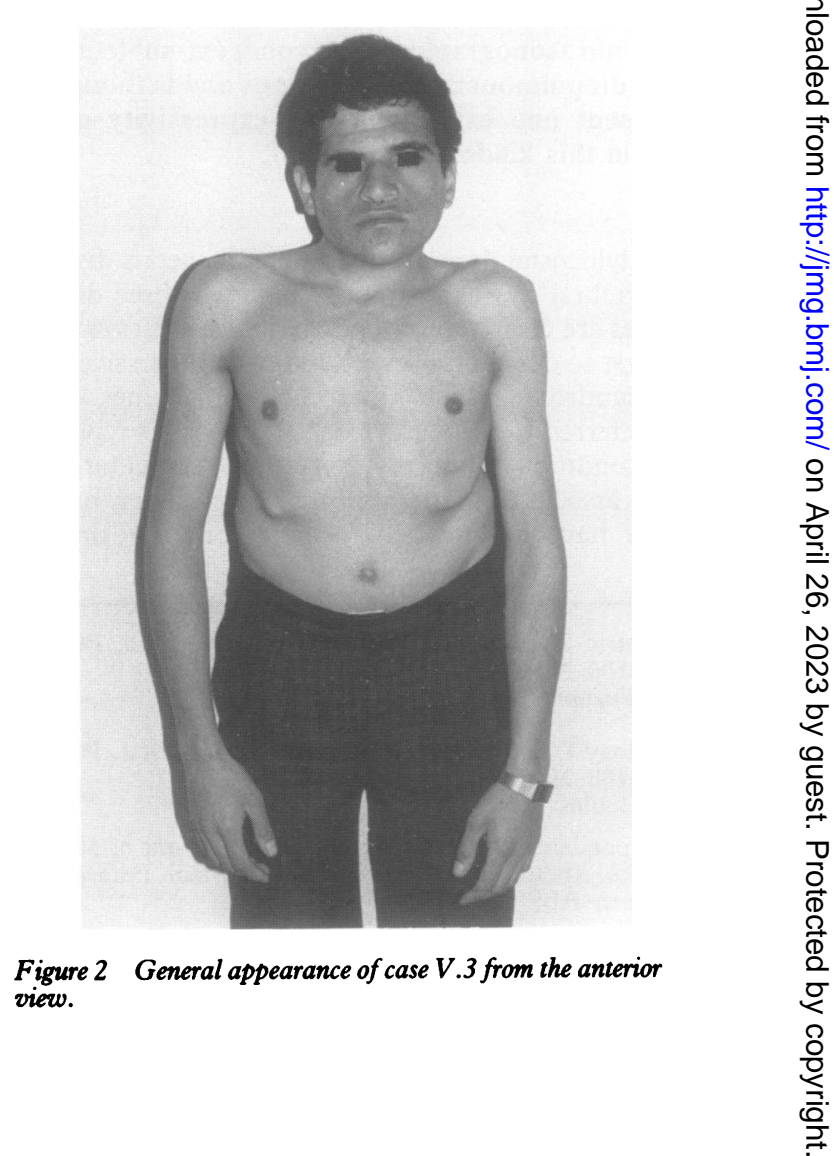


Clinical features of affected family members.

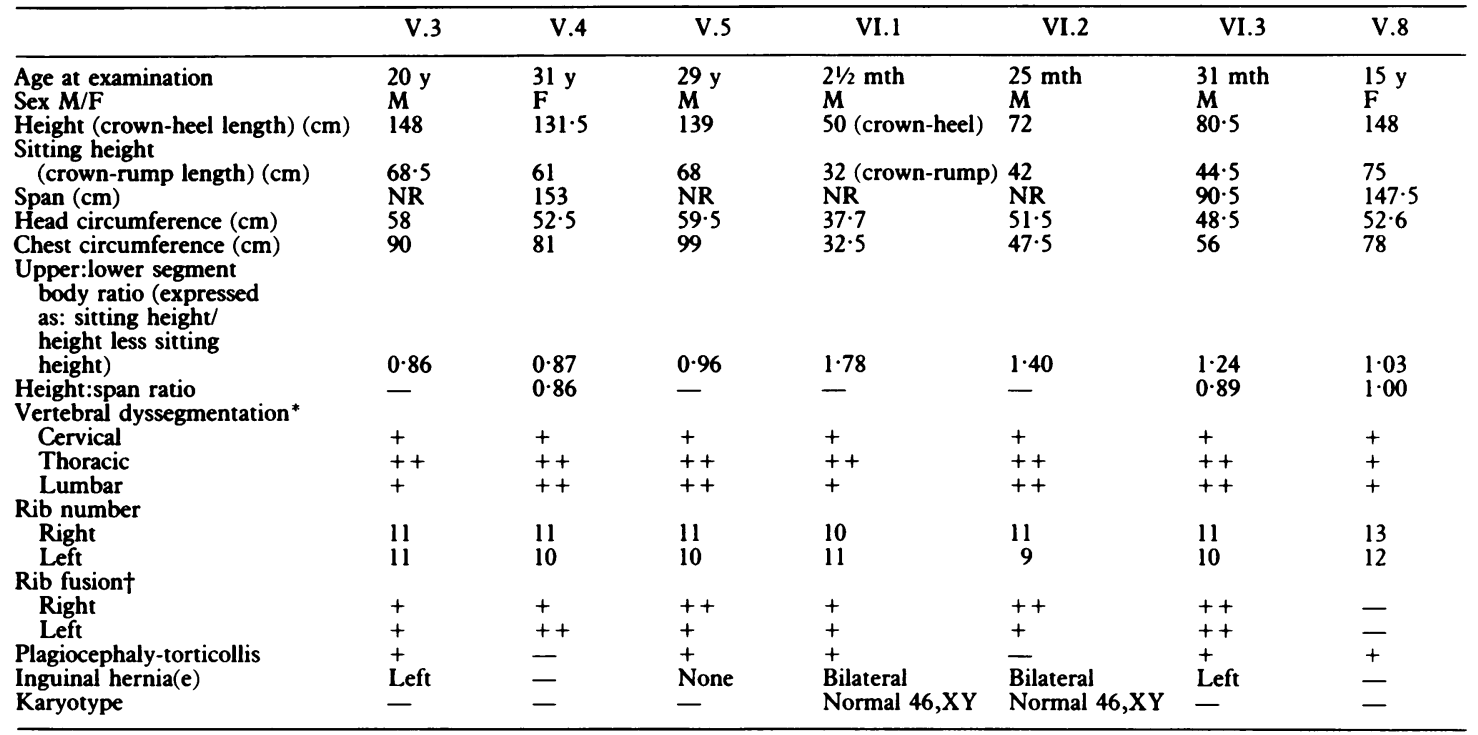

$*+=$ Relatively mild changes in the vertebrae. $++=$ Multiple hemivertebrae.

$t+=$ Fusion of ribs predominantly at their origins. $++=$ Fusion present also between the shafts of adjacent ribs. NR $=$ not recorded.

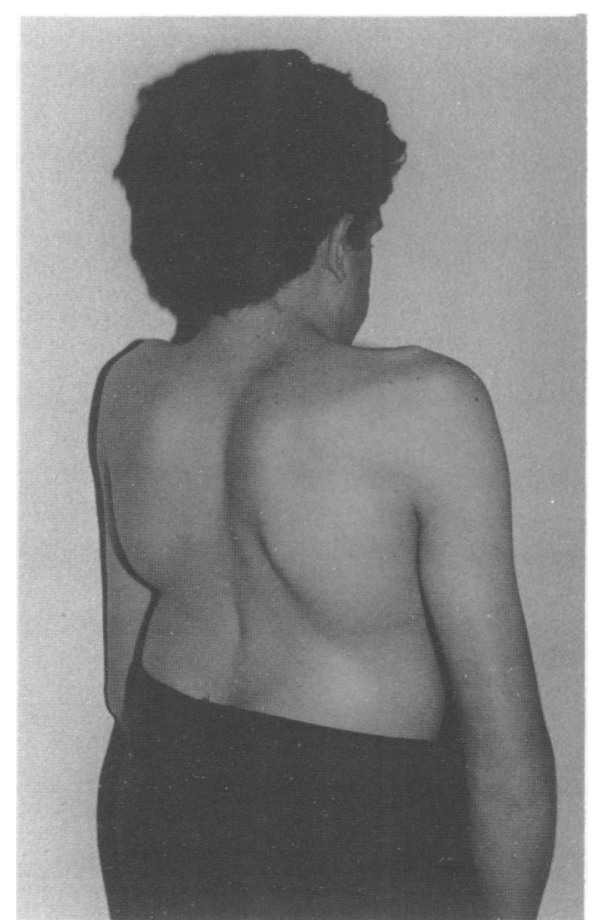

Figure 3 Oblique posterior view of case V.3.

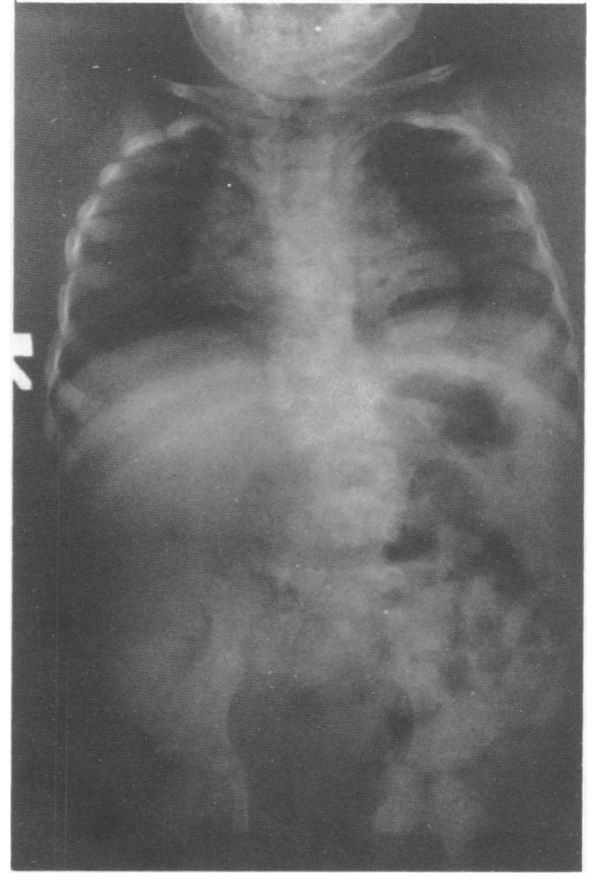

Figure 4 AP radiograph of the spine in case VI.3. 


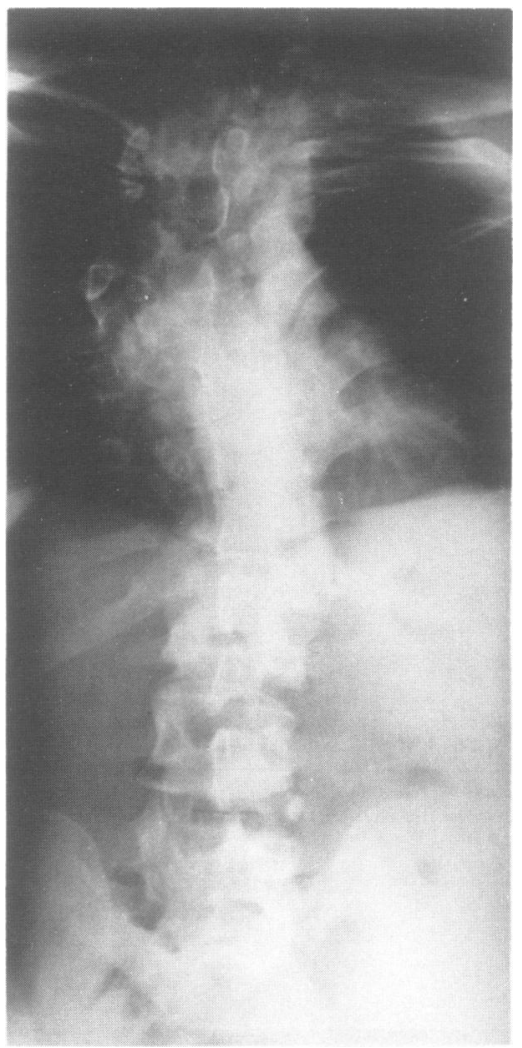

Figure 5 AP radiograph of the spine in case V.3.

the spinal cord is a theoretical risk. Figs 7 and 8 illustrate the mild changes found in the spine of case V.8. All cases had a similar degree of disruption of the cervical spine, and all the six severely affected subjects had a similar involvement of the thoracic spine. Involvement of the lumbar spine, as illustrated, was variable in extent. The obligatory carriers, V.1, V.2, V.6, and V.7, all had normal $x$ rays of the full spine.

Short stature was a marked feature in the affected subjects, ranging from $-3 \mathrm{SD}$ in VI.3 to $-6 \mathrm{SD}$ in V.4 and V.5. The upper to lower segment body ratios make it clear that short stature was the result of shortening of the vertebral column, although this is not so evident in V.5 despite severe dyssegmentation. This ratio must be related to age for a meaningful interpretation in the children. Although the data for the height:span ratio are incomplete, the measurement in two severely affected cases, V.4 and VI.3, emphasises disproportionate shortening of the vertebral column. Subject V.8 was a well proportioned subject whose centile height was greater than the severely affected cases but still low at just less than $-2 \mathrm{SD}$.

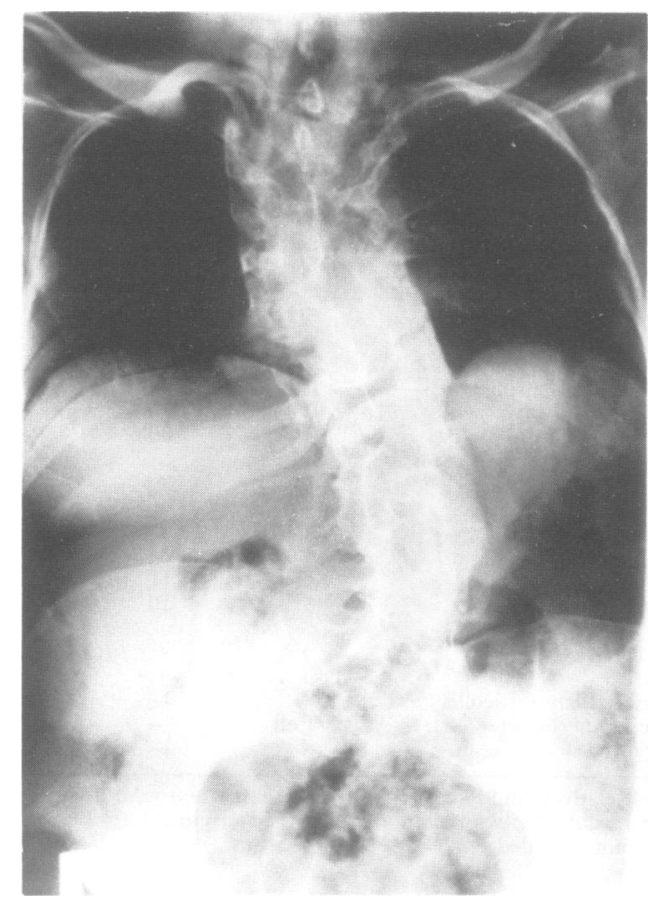

Figure 6 AP radiograph of the spine in case $V .4$.

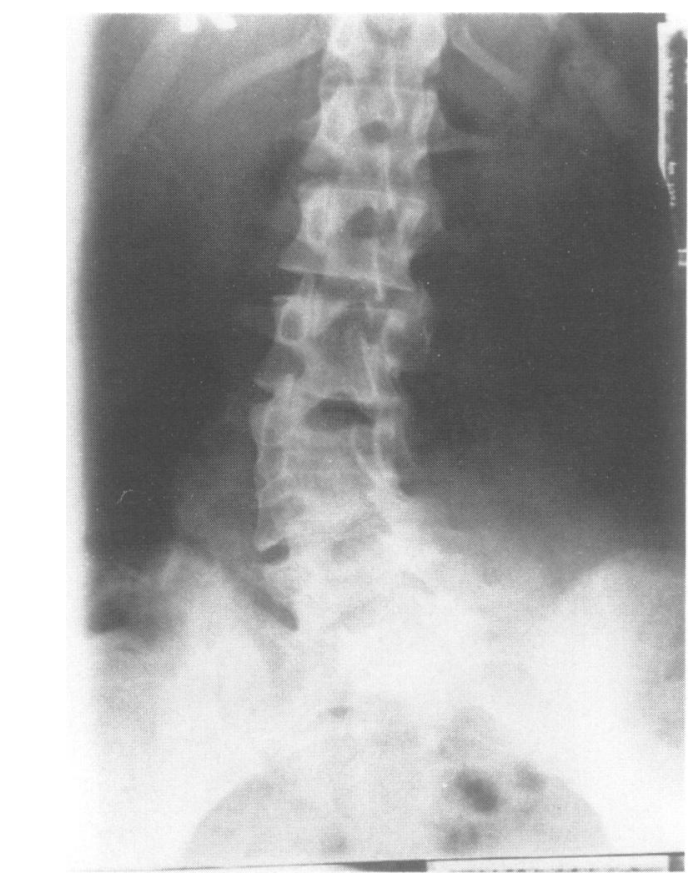

Figure 7 AP radiograph of the spine of case V.8 illustrating mild disruption of the lumbar spine. 


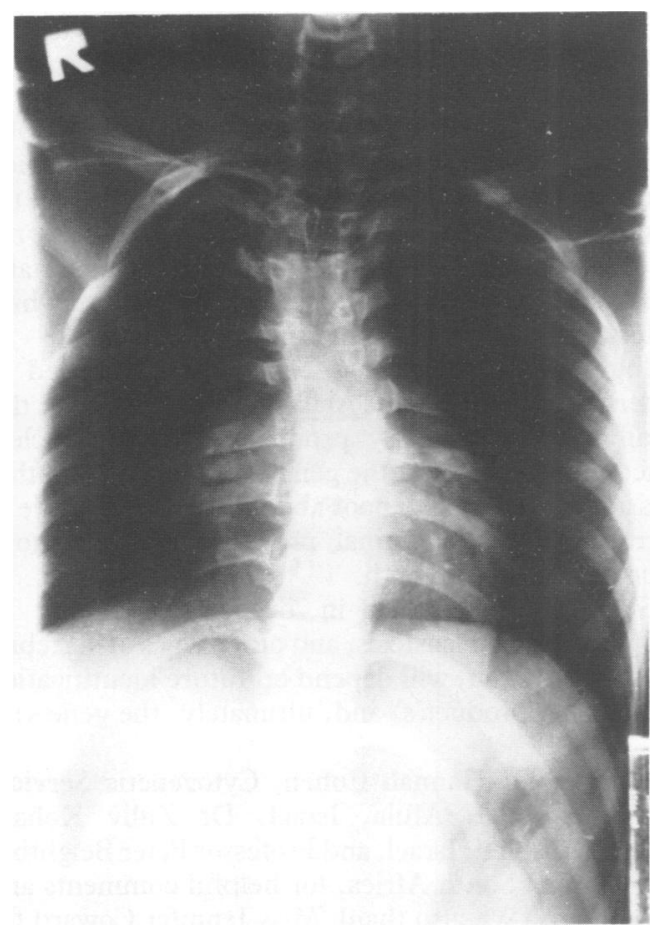

Figure 8 AP radiograph of the thoracic spine in case $V .8$.

The craniofacial dysmorphism, plagiocephalytorticollis sequence, was manifest in five subjects including V.8. Indeed, it was because of this that she was identified (fig 9). Cases V.4 (fig 10) and VI.2 had no obvious plagiocephaly and there was no apparent correlation of this dysmorphism with the extent of vertebral disruption.

The head circumference in cases V.3, V.5, and VI.2 was large (95th centile for VI.2 and $>97$ th centile for the other two). The sib of VI.2 had also been investigated for a large head, suggesting a separate familial macrocephaly in this part of the kindred.

Inguinal herniation was a prominent feature in males with four out of five affected, two of these bilaterally. Renal ultrasonography in all cases was normal. Karyotyping ( $G$ banding) was normal in the two cases studied.

The child VI.2 was born in another hospital. Prenatal ultrasound was performed because of the affected father but no spinal abnormality was detected.

\section{CASE VI.1}

This infant was beset with problems from birth, being a low birth weight baby of $2275 \mathrm{~g}$ at 37 weeks' gestation. By 3 months of age he had had two

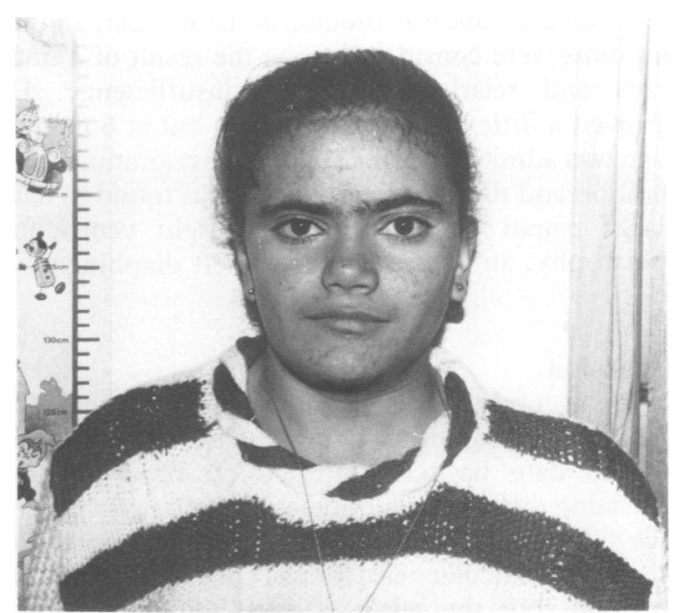

Figure 9 Appearance, showing plagiocephaly-torticollis sequence, of case $V .8$.

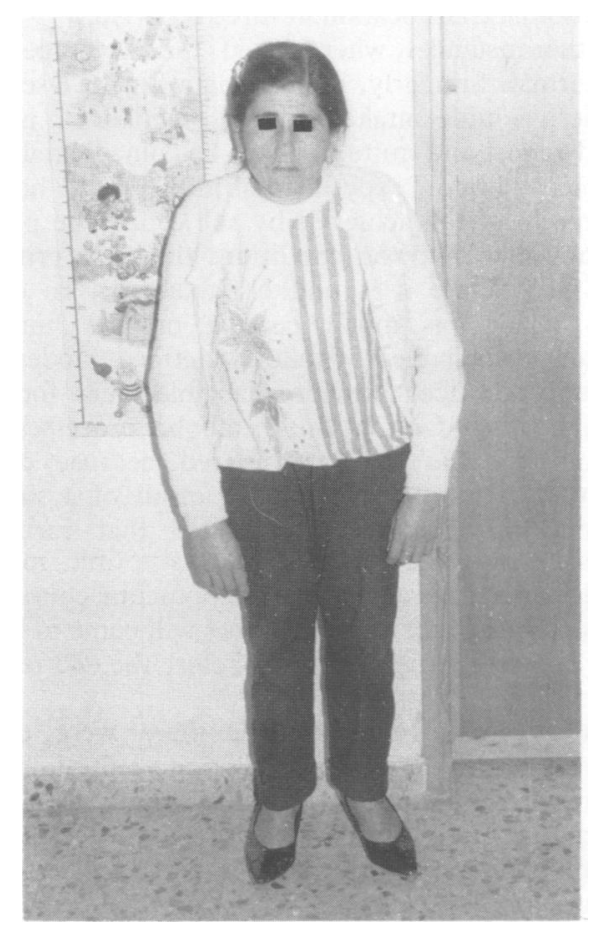

Figure 10 Case V.3 without craniofacial dysmorphism.

hospital admissions with aspiration pneumonia following vomiting and was diagnosed as having gastro-oesophageal reflux. From that time he failed to thrive and was again admitted at the age of $4 \frac{1}{2}$ months. A degree of right heart failure was present, 
an echocardiogram was thought to be normal, and his symptoms were considered to be the result of a small thorax and relative pulmonary insufficiency. He improved a little on diuretic therapy but at 6 months of age was admitted with a sudden deterioration of his condition and died. At necropsy he was found to have a large patent ductus arteriosus, right ventricular hypertrophy, and a membraneous left diaphragm.

\section{Discussion}

It is well accepted that spondylocostal dysostosis is a heterogeneous condition ${ }^{25}$ and much of the published work to date has concentrated on reporting and delineating different phenotypes and modes of inheritance. The question of variable gene expression within a particular entity has not been directly addressed, but the seven affected members of this kindred lend themselves to such an analysis.

The pedigree points to an autosomal recessive mode of inheritance and a single gene defect seems likely. The condition has been described in association with a chromosomal translocation in three reports, ${ }^{92627}$ but in all other instances, where tested, the karyotype has been normal. Similarly, the association with lysergic acid diethylamide intake in early pregnancy ${ }^{28}$ is an isolated report and quite likely to be coincidental. In the mouse embryo, experimental induction of hemivertebrae has been achieved by subjecting the pregnant mouse to hypoxic conditions during a critical period. ${ }^{29} 30$ While it is unlikely that such an exogenous insult has much bearing on the human condition, which clearly follows defined modes of inheritance, it does provide plausible clues for an aetiology which focuses on metabolic processes in embryological life that are altered because of a defective enzyme or protein, the result of a single mutant gene. It can be postulated that variable expressivity occurs because the susceptible mesodermal tissues have a diverse developmental course to run and many modifying influences will come to bear on the differentiating structures before the end result is realised.

In the cases of this study, there were clear variations in the degree of disruption of the lumbar vertebrae, and it could be argued on the basis of rib number that there was also a spectrum of disruption in the thoracic spine. Cases V.8 and VI.1 appear to be extremes in the spectrum of expressivity. While a large patent ductus arteriosus in VI.1 undoubtedly contributed to the death of the infant by secondary pulmonary hypertension and right heart failure, he had a membranous left diaphragm, also a mesodermally derived structure. The vertebral involvement in V.8 was so relatively mild that one cannot be sure whether she was, in fact, a homozygote or a heterozygote. None of the other large number of sibs, V.9 and V.10, was examined because none was volunteered by the family as an affected subject. It is therefore not known whether one or both parents, IV.1 and IV.2, were obligatory carriers.

It is recognised that the plagiocephaly-torticollis sequence can occur as a result of imbalanced cervical vertebrae. ${ }^{31} 32$ This is presumed to be the cause in the cases which manifest this deformation but it is not clear why V.4 and VI.2 were spared. One could also postulate that a separate linked gene is involved which is lost in some subjects through crossover.

Inguinal herniation has also been recognised in other cases of spondylocostal dysostosis, ${ }^{21}$ but in this family was particularly prominent. It is not clear whether this is part of the gene expression or whether it is acquired owing to poor abdominal musculature or increased intra-abdominal pressure secondary to a shortened trunk or both.

Significant advances in our understanding of spondylocostal dysostosis, and other types of vertebral dyssegmentation, will depend on future identification of the gene product(s) and, ultimately, the gene(s).

We thank Dr Hannah Cohen, Cytogenetic Service, Emek Hospital, Afula, Israel, Dr Zully Kohan, Kaplan Hospital, Israel, and Professor Peter Beighton, Cape Town, South Africa, for helpful comments and suggestions. We also thank Miss Jennifer Coward for secretarial assistance in preparing the manuscript.

1 Jarcho S, Levin PM. Hereditary malformation of the vertebral bodies. Bull fohns Hopkins Hosp 1938;62:216-26.

2 Lavy NW, Palmer CG, Merritt AD. A syndrome of bizarre vertebral anomalies. $\mathcal{f}$ Pediatr 1966;69:1121-5.

3 Pochaczevsky R, Ratner H, Perles D, Kassner G, Naysan P. Spondylothoracic dysplasia. Radiology 1971;98:53-8.

4 Perez-Comas A, Garcia-Castro JM. Occipito-facial-cervicothoracic-abdomino-digital dysplasia; Jarcho-Levin syndrome of vertebral anomalies. $\mathcal{F}$ Pediatr 1974;85:388-91.

5 Romero R, Ghidini A, Eswara MS, Seashore MR, Hobbins JC. Prenatal findings in a case of spondylocostal dysplasia type I (Jarcho-Levin syndrome). Obstet Gynecol 1988;71 (part 2): 988-91.

6 Tolmie JL, Whittle MJ, McNay MB, Gibson AAM, Connor JM. Second trimester prenatal diagnosis of the Jarcho-Levin syndrome. Prenat Diagn 1987;7:129-34.

7 Roberts AG, Conner AN, Tolmie JL, Connor JM. Spondylothoracic and spondylocostal dysostosis. 7 Bone foint Surg [Br] 1988;70:123-6.

8 Rimoin DL, Fletcher BD, McKusick VA. Spondylocostal dysplasia. A dominantly inherited form of short-trunked dwarfism. Am f Med 1968;45:948-53.

9 Temple IK, Thomas TG, Baraitser M. Congenital spinal deformity in a three generation family. $\mathcal{F}$ Med Genet 1988;25:831-4.

10 Floor E, DeJong RO, Fryns JP, Smulders C, Vles JSH. Spondylocostal dysostosis: an example of autosomal dominant transmission in a large family. Clin Genet 1989;36:236-41.

11 Cantu JM, Urrusti J, Rosales G, Rojas A. Evidence for autosomal recessive inheritance of costovertebral dysplasia. Clin Genet 1971;2:149-54.

12 Castroviejo IP, Rodriguez-Costa T, Castillo F. Spondylothoracic dysplasia in three sisters. Dev Med Child Neurol 1973;15: 348-54.

13 Franceschini P, Grassi E, Fabris C, Bogetti G, Randaccio M. The autosomal recessive form of spondylocostal dysostosis. Radiology 1974;112:673-5.

14 Bartsocas CS, Kiossoglou KA, Papas CV, Xanthou-Tsingoglou $M$, Anagnostakis DE, Daskalopoulou HD. Costovertebral dysplasia. Birth Defects 1974;X(No 9):221-6. 
15 Trindade CEP, Jose de Nobrega F. Spondylothoracic dysplasia in two siblings. Clin Pediatr 1977; 16:1097-9.

16 Silengo MC, Cavallaro S, Franceschini P. Recessive spondylocostal dysostosis: two new cases. Clin Genet 1978;13:289-94.

17 Beighton P, Horan FT. Spondylocostal dysostosis in South African sisters. Clin Genet 1981;19:23-5.

18 Young ID, Moore JR. Spondylocostal dysostosis. I Med Genet 1984;21:68-9.

19 Devos EA, Leroy JG, Braeckman JJ, Vanden Bulcke LJ, Langer LO. Spondylocostal dysostosis and urinary tract anomaly: definition and review of an entity. Eur f Pediatr 1978;128:7-15.

20 Casamassima AC, Morton CC, Nance WE, et al. Spondylocostal dysostosis associated with anal and urogenital anomalies in a Mennonite sibship. Am F Med Genet 1981;8:117-27.

21 Ayme S, Preus M. Spondylocostal/spondylothoracic dysostosis: the clinical basis for prognosticating and genetic counselling. Am $\mathcal{F}$ Med Genet 1986;24:599-606.

22 Castroviejo IP, Santolaya JM, Martin VL, Rodriguez-Costa T, Tendero A, Mulas F. Cerebro-facio-thoracic dysplasia: report of three cases. Dev Med Child Neurol 1975;17:343-51.

23 Wadia RS, Shirole DB, Dikshit MS. Recessively inherited costovertebral segmentation defect with mesomelia and peculiar facies (Covesdem syndrome). 7 Med Genet 1978;15:123-7.

24 Moerman P, Van den Berghe $K$, Fryns JP, Haspeslagh $M$ Lauweryns JM. A new lethal chondrodysplasia with spondylo- costal dysostosis, multiple internal anomalies and DandyWalker cyst. Clin Genet 1985;27:160-4.

25 Beighton P. Spondylocostal dysostoses. In: Inherited disorders of the skeleton. 2nd ed. Edinburgh: Churchill Livingstone, 1989.

26 Turpin R, Lejeune J, Lafourcade J, et al. Aberrations chromosomiques et maladies humaines. La polydysspondylie a 45 chromosomes. CR Acad Sci [D] (Paris) 1959;248:3636-8.

27 De Grouchy J, Mlynarski JC, Maroteaux P, et al. Syndrome polydysspondylique par translocation 14-15 et dyschondrosteose chez un meme sujet. Segregation familiale. C R Acad Sci [D] (Paris) 1963;256:1614-5.

28 Eller JL, Morton JM. Bizarre deformities in offspring of user of lysergic acid diethylamide. $N$ Engl F Med 1970;283:395-7.

29 Ingalls H, Curley FJ. Principles governing the genesis of congenital malformation induced in mice by hypoxia. $N$ Engl $\mathcal{f}$ Med 1957;257:1121-7.

30 Rivard $\mathrm{CH}$. Experimental induction of congenital vertebra malformations in mouse embryos. Presented at First International Orthopaedic Days, Nazareth, Israel, 29 October1 November 1989.

31 Clarren SK. Plagiocephaly and torticollis: etiology, natural history and helmet treatment. $\mathcal{F}$ Pediatr 1981;98:92-5.

32 Graham JM Jr. Smith's recognizable patterns of human deformation. 2nd ed. Philadelphia: Saunders, 1988:52. 